\title{
Management of concomitant pelvic floor disorders and gynecological malignancy: a clinical challenge
}

\author{
Gregor Prša ${ }^{1} \cdot$ Tamara Serdinšek $^{2}$
}

Received: 20 December 2021 / Accepted: 4 January 2022 / Published online: 24 January 2022

(c) The International Urogynecological Association 2022

Pelvic organ prolapse (POP) is a common condition, present to some degree in $40-60 \%$ of parous women [1]. Roughly $13 \%$ of women undergo surgery for prolapse or urinary incontinence (UI) in their lifetime [2]. Despite being a common condition, its coexistence with gynecological cancer is rarely reported [3]. In cases of concomitant diseases, patients are usually treated by a gynecological oncologist without a full evaluation and therapeutic intervention for their POP or UI, as the life-saving cancer surgery is the primary focus. POP/UI treatment, thought to be secondary, is therefore often delayed or completely ignored, despite being an important factor for the patient's overall quality of life [4]. In the literature, nearly two thirds of women with a gynecological malignancy reported symptoms of UI, POP, or both prior to the beginning of oncological treatment. Almost 20\% rated their symptoms as moderate to severe [5]. Additionally, Del Priore et al. found that $60 \%$ of gynecological oncology patients reported at least one symptom of UI and $23 \%$ of them had severe symptoms [6].

Because of the rarity of literature describing the management of both coexisting disorders, the best treatment approach is not clearly defined and varies greatly between different types of gynecological malignancies and different degrees of POP and UI. However, as with most gynecological cancers, stress urinary incontinence and POP are treated surgically. Consequently, patients with concomitant pelvic floor disorder and gynecological cancer may benefit from a simultaneous resolution of both disorders. Concurrent surgery may result in a reduction of costs of care, as

Gregor Prša

prsagregor93@gmail.com

1 Department for Gynecology and Obstetrics, General Hospital Murska Sobota, Ulica dr. Vrbnjaka 6, 9000 Murska Sobota, Slovenia

2 Department of General Gynaecology and Urogynaecology, Clinic for Gynaecology and Perinatology, University Medical Centre Maribor, Ljubljanska 5, 2000 Maribor, Slovenia well as fewer surgical complications, a shorter duration of hospitalization, and an improved quality of life [5, 6]. More patients with endometrial and cervical cancer are diagnosed with an early-stage disease that can be cured with surgical intervention. These patients are more likely to become longterm cancer survivors, consequently benefiting more from a combined approach to their gynecological malignancy and their POP and/or UI [5].

Only a few studies are available that address the management of patients with a gynecological malignancy complicated by POP/UI, making it difficult to make any recommendations [7, 8]. Therefore, until more data are available, we feel that the management of these cases should be multidisciplinary, involving a urogynecologist, a gynecological oncologist, an oncological internist, and a radiologist. Their aim should be the optimal oncological treatment with an evaluation of the ability to achieve proper surgical treatment of POP/UI. The evaluation of the patient's comorbidities, extent of POP, age, and compliance should be mandatory. Furthermore, required radiotherapy and chemotherapy treatment should be taken into consideration. It would be beneficial if these cases were reported more thoroughly and frequently in the future, especially by high-volume medical centers with a large body of experience. Developing a large data set evaluating different approaches and success of treatment could be of great value for the development of much needed guidance for proper management of patients with combined gynecological malignancies and POP/UI.

\section{References}

1. Maher C, Feiner B, Baessler K, Schmid C. Surgical management of pelvic organ prolapse in women. Cochrane Database Syst Rev. 2013;4:CD004014.

2. Raju R, Linder BJ. Evaluation and management of pelvic organ prolapse. Mayo Clin Proc. 2021;96(12):3122-9.

3. Matsuo K, Fullerton ME, Moeini A. Treatment patterns and survival outcomes in patients with cervical cancer complicated by 
complete uterine prolapse: a systematic review of literature. Int Urogynecol J. 2016;27(1):29-38.

4. Chung CP, Dao NT, Wakabayashi MT, Dellinger TH, Lee SJ, Han ES. Concurrent pelvic reconstruction and minimally invasive pelvic cancer surgery. Int Urogynecol J. 2018;29(11):1709-11.

5. Thomas SG, Sato HRN, Glantz JC, Doyle PJ, Buchsbaum GM. Prevalence of symptomatic pelvic floor disorders among gynecologic oncology patients. Obstet Gynecol. 2013;122(5):976-80.

6. Del Priore G, Taylor SY, Esdaile BA, Masch R, Martas Y, Wirth $\mathrm{J}$. Urinary incontinence in gynecological oncology patients. Int $\mathrm{J}$ Gynecol Cancer. 2005;15(5):911-4.

7. Ota Y, Suzuki Y, Matsunaga T, Ninomiya R, Kagimoto S, Miyagi E. New combined surgery for cervical cancer complicated by pelvic organ prolapse using autologous fascia lata: a case report. Clin Case Rep. 2020;8(8):1382-6.

8. Vanichtantikul A, Tharavichitkul E, Chitapanarux I, Chinthakanan O. Treatment of endometrial cancer in association with pelvic organ prolapse. Case Rep Obstet Gynecol. 2017;2017:1-3.

Publisher's note Springer Nature remains neutral with regard to jurisdictional claims in published maps and institutional affiliations. 